\title{
First Language Proficiency as a Facilitator in Foreign/ Second Language Acquisition: A Case Study in the Kingdom of Saudi Arabia
}

\author{
Mohammed Marajan Awad Adam \\ College of Science and Arts, Qassim University, Saudi Arabia \\ E-mail: mmarajan@yahoo.com
}

\author{
Received: 02-10-2015 \\ Accepted: 04-01-2016 \\ Advance Access Published: January 2016 \\ Published: 01-03-2016 \\ doi:10.7575/aiac.ijalel.v.5n.2p.220 \\ URL: http://dx.doi.org/10.7575/aiac.ijalel.v.5n.2p.220
}

\begin{abstract}
English is taught as a foreign language in the Arab world even though practical concerns call for greater emphasis on the language. In all personal interactions too Arabic is the preferred language. Thus the environment for English is really very limited as by the time the learners are exposed to the language they are well entrenched in Arabic. While this may be a handicap in some EFL situations (for example where adults are concerned), in the Arab context this can prove a big boon. This is because young language learners who are proficient in their first language can apply the learning techniques while acquiring the second language. This paper targets the teaching fraternity in the Arab world to help them understand how first language proficiency can aid second/foreign language acquisition.
\end{abstract}

Keywords: language acquisition, Saudi EFL learners, language proficiency, Arabic as a first language

\section{Introduction}

In the Arab world, the mother tongue Arabic is the first language as also the sole language of all personal and professional use. English is introduced as a Foreign Language, usually a few years after they join school. Thus by the time the learners are exposed to the language, they are already well entrenched linguistically in the mother tongue. Another factor worth mentioning is the fact that by this time they have lost a couple of years in the Critical Age which is a significant factor in language acquisition. In the schools, the Play Way pedagogy is encouraged in the private sector whereas the government schools are still stuck with the now obsolete Grammar Translation Method. It would not be an exaggeration to say (and as a researcher, I take leave to say this authoritatively) that the learning outcome in either case is far from satisfactory. Needless to say, the medium of instruction remains Arabic across all levels. Concerns for the pristine Arab culture, language and religion, all of which are a result of the grace of Allah, have prevented greater inclusion of English in the curriculum. However, with a rapidly shrinking world and greater consonance among the economies, English proficiency is becoming more and more desirable. Personal and professional success are becoming closely linked with one's fluency in the language. Accordingly, the need of the situation is for the teaching community to utilize the Arab learners' background knowledge of the MT to enhance their EFL skills. Various Studies in the West also suggest, that ELLs who enter the school system with a solid background in their native language develop proficiency in the English language more quickly than those who arrive with no or little literacy skills in their first language (Genesee, Lindholm-Leary, Saunders, \& Christian, 2005). This and other such studies encouraged the current research to create the hitherto missing link between ELL's MT proficiency and their English acquisition.

We may reiterate here that it is advantageous to both educators and students to understand the role adolescents' first language plays in the acquisition of their second language. ELLs may benefit from this study, which may help them understand that they may use the prior knowledge in their first language to develop new and proper understanding of the English language. They may make connections with their language while using it as a ground for developing the new language being learnt. Educators may also benefit from this study, perhaps also developing a different perception of the relationship between learners' first language and their second language acquisition. In addition, understanding the contribution a native language can bring to the learning of a new language a scaffold for building new knowledge.

Finally, this study may be regarded as one of immense value to the entire KSA community: Policy makers, educators, administrators, academicians, researchers, planners, linguists and the public at large.

\section{Literature review}

Research conducted by Cummins (2000), a specialist in language learning and bilingualism, and Faltis and Coulter (2008), experts in bilingualism and in the education of immigrant students, showed that ELLs who have had academic experience appropriate to their age group and who are adequately proficient in their native language perform quite well, as opposed to less fortunate ELLs who arrive in school with little or no academic and linguistic experience. It appears that the use of conventional reading methods presents a particular challenge for students who are illiterate in their first language. Faltis and Coulter asserted that the learners' future functioning in a second language is built upon their ability 
in their first language. Cummins (2001) also supported the idea that first language plays a role in learning a second language; he added his opinion with force that the students who enter school in the United States and who are able to read and write in their native language not only learn English more quickly but are also able to use their first language as a learning tool.

It is the generally held opinion of most researchers that the process of acquiring a second language is a phenomenon. It does not happen overnight. Research shows that learning a language requires ample time (Krashen \& Terrel, 2000). It is also a fact, proved by research that not everyone learns a new language at the same pace (Cummins, 2000). Krashen and Terrel (2000), proponents of the natural approach theory, explained that competence in a language develops over time: they opine that it is acquired through input that is beyond the learner's actual level of comprehension and performance. This is where the teachers' role is crucial in facilitating the process of developing language competence through expert tailoring of their instruction. The more knowledgeable educators are about the language acquisition process, the better equipped they are to work with ELLs (American Federation of Teachers, 2007; Northwest Regional Educational Laboratory, 2004).

Cummins (2000) not only agreed that time is of essence in the process of learning/acquiring a new language, but he also affirmed that students who are literate in their first language develop proficiency in the English language more quickly than those who are not. He later shared the result of a study conducted in Canada that determined that students who were enrolled in a French/English bilingual program performed better than those who were enrolled in an English-only program (Cummins, 2000). Stephen Krashen, an expert in the field of linguistics who specializes in theories of language acquisition and development, also shared his idea regarding second language acquisition. In an article written for USA Today, Krashen (2002) explained that children who can read in their native language rapidly transfer the reading ability to English. Slavin and Cheung (2004), educational researchers, also agreed with this theory: they observed that students' ability to read in their native language activates their reading performance in English. Considerable research had been conducted on second language acquisition (Calderon, 2007; Calderon \& Minaya-Rowe, 2003; Cummins, 2000; Garcia, 2005). However, it is still not known what impact adolescents' literacy in their first language has on their second language acquisition.

Some theorists (Chamot, Barnhart, El-Dinary, \& Robbins, 1999; Genesee et al., 2005) argued that literacy skills may transfer from one language to another. The most pertinent question is how the skills acquired in one language transfer to another language. Bialystok (2001), Garcia (2005), and Calderon and Minaya-Rowe (2003), among others, claimed that skills, such as those in language structure and grammar, enable the learners to make connections between their native language and the language being learned. However, it is worth examining as to what role age factor plays in the process. Again, it is necessary to know how adolescents' potential to acquire a new language compares to that of younger children's. Piaget's (1947/2001) theory of learning seems applicable to this issue; per his stages of development, certain things are learned at a certain age. Thus, some knowledge transfer that may be possible during adolescence may not be possible in younger children. If this is the case, some of the skills learned in the first language may not be transferable to the second language, and rather other skills may facilitate the learning of a new language.

So, building on existing literacy skills to develop literacy in a new language may be necessary. As a matter of fact, Vygotsky (1986/2003) encouraged educators to work in the students' zone of proximal development (ZPD) with the understanding that students' prior knowledge may be used as a basis for construction to bring them up to their potential level of development. This can be achieved through assistance from peers or an instructor if the environment permits such learning to take place (Alexander, 2006). The way a classroom is organized to support the acquisition of English literacy is a function of teaching and learning (Brooks \& Brooks, 1999). In fact, Cummins (2001) explained that if students are already involved in cognitive operations using language that requires them to analyze, synthesize, and summarize, they can easily transfer these skills to a second language. However, among adolescent newcomers are those who have not had the opportunity to develop literacy skills even in their first language (Burt, Peyton, \& Adams, 2003).

\subsection{Research Questions}

1. What is the role of first language literacy skills of adolescents living in KSA on their second language acquisition?

2. How do skills in the first language transfer to the English language being learned?

3. If the transfer of skills is possible, how do literacy skills in the first language promote the acquisition of the second language?

4. Does the environment in KSA promote learning of the second language?

\section{Methodology}

The mixed methods approach was used to study the facilitation extended to the literacy of adolescents living in Methnab city, Qassim Province, Saudi Arabia in their first language on their second language acquisition. A group of 26 Arabic-speaking adolescent ELLs from grades 12 who attended two high schools, and who were exposed to the same academic experiences participated in the study. After careful examination of the research problem, it appeared that a thorough study of the research questions would entail the use of qualitative as well as quantitative strategies. Both text and data analyses were used to study the relationship between the variables: adolescents' literacy in the first language and second language learning. Accordingly, descriptive and inferential statistical tools were used for data analysis. The numerical data, comprising of students' test scores and coded answers to closed-ended questions on a questionnaire, provided specific measurements of the variables in question (Creswell, 2005). The process for collecting quantitative 
data during the research required the use of predetermined and pretested instruments to measure the relationship between the two variables (Creswell, 2005). The students' scores in the city standardized examinations were examined. After collecting the data, through the use of the SPSS computer software program, the analysis of variance (ANOVA) was done to determine the statistical relationship between the two variables.

Quantitative research requires the use of pre-determined and pre-tested valid and reliable instruments (Creswell, 2005). To measure the relationship between the variables of study, standardized test results were used. A correlational research methodology was used because the test scores are numerical data that specifically measure the students' literacy ability in their first language and their progress toward achieving proficiency in the English language. Such data is graphically represented to facilitate interpretation.

The qualitative data collection technique that was used for the study was the in-depth interview. This technique was presented in the form of a questionnaire. The teachers of ELLs completed a questionnaire written in English. ELL students had the choice to complete a questionnaire either in English or in Arabic and to write the responses to the openended questions in the language they felt more comfortable using.

The study was conducted at two public high schools ( Boys \& Girls) located in Methnab, Qassim, Saudi Arabia. These particular schools were chosen for the study because all its student population consisted of ELLs, all from the same city where Arabic is the official language. This is also a school very much sought by ELLs because of the programmes offered. The ELL programme is unique because it combines English as a second language (ESL) programmed with the opportunity for support in first language instruction.

It was originally intended to conduct the study with 50 students; but because of missing data, 26 students participated. Thus, the sample size consisted of a group of 26 Arabic speaking adolescent ELLs who attended two schools, were in the same grade (12), were exposed to similar academic experiences, were administered English as a Second Language Subject Test for the first time in the spring of 2011, and had taken the Arabic and the English Language in the annual examinations. These students are given the same opportunities. They receive mandated ESL services pertaining to their English language proficiency level as required by the city regulations, and are also offered voluntary participation in native language arts classes.

\section{Analysis}

The statistical computer program SPSS was used for the purpose of generating tables to summarize the information supplied by the teacher, and student surveys and the students' tests scores. The responses to the survey were first scored. A numerical value was assigned to each response as suggested by Creswell (2005, p. 175). The same numeric system was used to score the responses to the questions of all three surveys from teachers and students.

After scoring the data, ANOVA was conducted through SPSS, which was used to analyze the data. The data was input into the system. I performed statistical analyses to fully discover the patterns and meanings the data holds (Leedy \& Ormrod, 2005, p. 249). Descriptive statistics was used to find the mean, mode, and median of the test scores because they indicate general tendencies in the data (Creswell, 2005, p. 181). Inferential statistics was also used because it not only allowed me to compare the adolescent ELLs who are literate in their first language to those who are not literate in their first language but also allowed me to draw conclusions about the population of adolescent ELLs living in Methnab.

\subsection{Descriptive Data: English Language Learners (ELLs)}

Male and female 12th-grade Arabic-speaking students from 17 to 21 years age-band who belonged to the same city participated in the study. These students have been attending the same public high school, have been exposed to the same academic experience, were or have been enrolled in English as a second language (ESL) subject programme, were administered the same annual examinations for the first time in 2011; and afterwards in 2012 and again in 2013. Their annual examination scores were available from the school records to determine their progress in achieving proficiency in English; they had taken the annual examinations in both Arabic and English.

The quantitative data consisted of the students' standardized annual examination results in English as a Foreign/Second Language and Arabic as first language and of the answers to the closed-ended questions of the teacher and student surveys. Answers to the open-ended questions of the student constituted the qualitative data. Two surveys were used. The surveys were different in terms of the information that should be gathered for each type of participant (i.e., students and teachers). The teacher surveys were hand-delivered, and the student surveys were completed in a separate session organized after school.

Descriptive statistics are also presented in order to characterize the participants. Inferential statistics, analysis of variance (ANOVA) and Correlation are also discussed in order to answer the research questions.

Pertinent information about the students' literacy information scores across the years 2011, 2012, and 2013 was gathered. Table 1 shows the descriptive data of the students regarding their annual examinations on listening and speaking, and Table 2 shows results for reading and writing. 
Table 1. Descriptive Data on Listening and Speaking

\begin{tabular}{|c|c|c|c|c|c|}
\hline Year & $N$ & $\begin{array}{l}\text { Mini } \\
\text { mum }\end{array}$ & Maximum & Mean & Std deviation \\
\hline 2011 & 26 & 565 & 717 & 680.85 & 42.07 \\
\hline 2012 & 24 & 613 & 777 & 685.46 & 38.04 \\
\hline 2013 & 23 & 659 & 797 & 716.96 & 36.17 \\
\hline Level & \multicolumn{2}{|c|}{ Frequency } & Percent & Valid percent & Cumulative percent \\
\hline \multicolumn{6}{|l|}{2011} \\
\hline Beginner & 08 & & $30.77 \%$ & $30.77 \%$ & $30.77 \%$ \\
\hline Intermediate & 13 & & $50.00 \%$ & $50.00 \%$ & $80.77 \%$ \\
\hline Advanced & 03 & & $11.54 \%$ & $11.54 \%$ & $92.31 \%$ \\
\hline Proficient & 02 & & $7.69 \%$ & $7.69 \%$ & $100.00 \%$ \\
\hline Total & 2 & & $100.00 \%$ & & \\
\hline \multicolumn{6}{|l|}{2012} \\
\hline Beginner & 0 & & $3.85 \%$ & $3.85 \%$ & $3.85 \%$ \\
\hline Intermediate & 10 & & $38.46 \%$ & $38.46 \%$ & $42.31 \%$ \\
\hline Advanced & 05 & & $34.62 \%$ & $34.62 \%$ & $76.93 \%$ \\
\hline Proficient & 0 & & $15.38 \%$ & $15.38 \%$ & $92.31 \%$ \\
\hline Missing & 02 & & $7.69 \%$ & $7.69 \%$ & $100.00 \%$ \\
\hline Total & 26 & & $100.00 \%$ & & \\
\hline \multicolumn{6}{|l|}{2013} \\
\hline Intermediate & $0^{7}$ & & $26.92 \%$ & $26.92 \%$ & $26.92 \%$ \\
\hline Advanced & 06 & & $23.08 \%$ & $23.08 \%$ & $50.00 \%$ \\
\hline Proficient & 10 & & $38.46 \%$ & $38.46 \%$ & $88.46 \%$ \\
\hline Missing & 03 & & $11.54 \%$ & $11.54 \%$ & $100.00 \%$ \\
\hline Total & 2 & & $100.00 \%$ & & \\
\hline
\end{tabular}

Table 2. Annual Exam Descriptive Data, Reading and Writing

\begin{tabular}{|c|c|c|c|c|c|}
\hline Year & $N$ & Minimum & Maximum & Mean & Std deviation \\
\hline 2011 & 26 & 611 & 735 & 686.96 & 31.58 \\
\hline 2012 & 24 & 638 & 742 & 682.88 & 30.33 \\
\hline 2013 & 23 & 661 & 761 & 697.35 & 29.73 \\
\hline Level & Frequency & & Percent & Valid percent & Cumulative percent \\
\hline \multicolumn{6}{|l|}{2011} \\
\hline Beginner & 3 & & $11.54 \%$ & $11.54 \%$ & $11.54 \%$ \\
\hline Intermediate & 12 & & $46.15 \%$ & $46.15 \%$ & $57.69 \%$ \\
\hline Advanced & 9 & & $34.62 \%$ & $34.62 \%$ & $92.31 \%$ \\
\hline Proficient & 2 & & $7.69 \%$ & $7.69 \%$ & $100.00 \%$ \\
\hline Total & 26 & & $100.00 \%$ & $100.00 \%$ & \\
\hline \multicolumn{6}{|l|}{2012} \\
\hline Beginner & 2 & & $7.69 \%$ & $7.69 \%$ & $7.69 \%$ \\
\hline Intermediate & 14 & & $53.85 \%$ & $53.85 \%$ & $61.54 \%$ \\
\hline Advanced & 7 & & $26.92 \%$ & $26.92 \%$ & $88.46 \%$ \\
\hline Proficient & 1 & & $3.85 \%$ & $3.85 \%$ & $92.31 \%$ \\
\hline Missing & 2 & & $7.69 \%$ & $7.69 \%$ & $100.00 \%$ \\
\hline Total & 26 & & $100.00 \%$ & $100.00 \%$ & \\
\hline \multicolumn{6}{|l|}{2013} \\
\hline Intermediate & 15 & & $57.69 \%$ & $57.69 \%$ & $57.69 \%$ \\
\hline Advanced & 5 & & $19.23 \%$ & $19.23 \%$ & $76.92 \%$ \\
\hline Proficient & 3 & & $11.54 \%$ & $11.54 \%$ & $88.46 \%$ \\
\hline Missing & 3 & & $11.54 \%$ & $11.54 \%$ & $100.00 \%$ \\
\hline Total & 26 & & $100.00 \%$ & $100.00 \%$ & \\
\hline
\end{tabular}


From Table 1, it can be seen that collectively as the years progressed, the mean of the score of the students for listening and speaking increased. From a mean 680.85 in 2011, it went up to 685.46 in 2012 and 716.96 in 2013. This shows that there seems to be a growth in terms of listening and speaking literacy of students in the English language in the aforementioned years. Specifically, the number of students that were labeled as 'Advanced' increased as the year progresses and the same phenomena is seen at the 'Proficient' level.

From Table-2, it can be seen collectively that the development that was observed in listening and speaking was not observed for reading and writing. Although from 2011 to 2013, the mean score of the students increased from 686.96 to 697.35, a decrease can be observed from 2011 to 2012 (686.96 to 682.88).

The fluctuation means that the progress of the students in the reading and writing aspects of English literacy was not stable and could have decreased or increased at any point of time. This fluctuation was also evident in the number of students that fell under each category viz. Beginner, Intermediate, Advanced, and Proficient. For this reason it is better to consider the collective outcomes to arrive at year-wise results.

\subsection{Teachers}

Ten teachers were included in this study. The teachers answered a questionnaire containing 20 items designed to substantiate the answers of the students and provide insights for the objectives of this research. The descriptive data from the answers to the teacher questionnaire were analysed to arrive at generalized observations. For example, if, in response to question 02 , six out of ten teachers answer option 1 then this is taken as the generalization for this question. In other words, the most chosen option is used in the current study. The data collected from the teachers' questionnaire as stated earlier is only descriptive, meant to supplement the students' data.

Table 3. Teachers' responses to the items in the questionnaire

\begin{tabular}{|c|c|c|}
\hline Question no. & $\begin{array}{l}\text { Teacher } \\
\text { responses }\end{array}$ & Generalization \\
\hline 1 & $10 / 10$ & Over 10 years of total teaching experience \\
\hline 2 & $8 / 10$ & 5-10 years of teaching English \\
\hline 3 & $10 / 10$ & Dealt with all levels of English teaching \\
\hline \multicolumn{3}{|l|}{4} \\
\hline 5 & $6 / 10$ & Only the advanced learners are proficient in English \\
\hline 6 & $8 / 10$ & Only literate students move towards proficiency \\
\hline 7 & $9 / 10$ & Only first lg literates move towards SLA \\
\hline 8 & $9 / 10$ & ELLs in KSA do not engage in academic conversation \\
\hline 9 & $10 / 10$ & SLA rarely occurs naturally \\
\hline 10 & $10 / 10$ & Generally students dislike reading \\
\hline 11 & $10 / 10$ & Teachers encourage all students to read \\
\hline 12 & $9 / 10$ & Only advanced ELLs are proficient in their first language \\
\hline 13 & $2 / 10$ & Proficient readers sometimes read for pleasure \\
\hline 14 & $9 / 10$ & First $\lg$ literates achieve SL literacy faster \\
\hline 15 & $9 / 10$ & ELL's first lg contributes to their SLA \\
\hline 16 & $6 / 10$ & Students sometimes translate from English to first lg \\
\hline 17 & $6 / 10$ & Students refer to First $1 \mathrm{~g}$ reading strategies in the English classroom \\
\hline 18 & $7 / 10$ & Literacy skills from first $1 \mathrm{~g}$ can be transferred to SLA \\
\hline 19 & $6 / 10$ & Literacy skills in FL influence English acquisition \\
\hline 20 & $6 / 10$ & Relationship between first lg acquisition and SLA is 'Good' \\
\hline
\end{tabular}

The data tabulated above is immensely valuable owing to the teacher feedback on generalizations that can be drawn about the English classroom in KSA. 
Table 4. Student Proficiency Level

\begin{tabular}{|c|c|c|c|c|}
\hline 2011 & 2012 & 2013 & $\begin{array}{l}\text { Progress (2011- } \\
2012)\end{array}$ & $\begin{array}{l}\text { Progress (2012- } \\
2013)\end{array}$ \\
\hline I & I & I & $\mathrm{Y}$ & $\mathrm{Y}$ \\
\hline I & I & I & $\mathrm{N}$ & $\mathrm{N}$ \\
\hline B & B & I & $\mathrm{N}$ & $\mathrm{Y}$ \\
\hline I & I & A & $\mathrm{N}$ & $\mathrm{Y}$ \\
\hline A & A & A & $\mathrm{N}$ & $\mathrm{Y}$ \\
\hline I & I & I & $\mathrm{N}$ & $\mathrm{Y}$ \\
\hline I & A & A & Y & $\mathrm{N}$ \\
\hline B & B & I & Y & $\mathrm{N}$ \\
\hline I & I & I & Y & $\mathrm{N}$ \\
\hline B & I & I & Y & $\mathrm{N}$ \\
\hline B & B & I & $\mathrm{N}$ & $\mathrm{Y}$ \\
\hline I & A & A & Y & $\mathrm{N}$ \\
\hline I & A & A & $\mathrm{N}$ & $\mathrm{Y}$ \\
\hline I & I & I & $\mathrm{N}$ & $\mathrm{Y}$ \\
\hline B & I & I & Y & $\mathrm{Y}$ \\
\hline B & I & I & Y & $\mathrm{N}$ \\
\hline I & A & A & Y & $\mathrm{Y}$ \\
\hline B & I & I & $\mathrm{N}$ & $\mathrm{Y}$ \\
\hline B & I & I & Y & $\mathrm{Y}$ \\
\hline I & A & $P$ & Y & $\mathrm{Y}$ \\
\hline I & A & $P$ & Y & $\mathrm{Y}$ \\
\hline I & I & I & $\mathrm{N}$ & $\mathrm{Y}$ \\
\hline I & I & I & Y & $\mathrm{Y}$ \\
\hline I & I & I & Y & $\mathrm{Y}$ \\
\hline I & I & I & Y & $\mathrm{Y}$ \\
\hline A & A & A & $\mathrm{N}$ & $\mathrm{Y}$ \\
\hline
\end{tabular}

Note. Proficiency level scale: $\mathrm{B}=$ Beginner, $\mathrm{I}=$ Intermediate, $\mathrm{A}=$ Advanced, $\mathrm{P}=$ Proficient .

In this table $\mathrm{Y}$ stands for positive progress in the student's proficiency and $\mathrm{N}$ stands for no progress. Allowing a weightage of +1 for every $\mathrm{Y}$ and of -1 for every $\mathrm{N}$, we arrive at the total scores of +34 and-18. Thus the cases showing a positive improvement far outweigh the cases reporting $\mathrm{N}$ that is, no progress. This analysis also goes towards validating our hypothesis that First Language Proficiency is a positive factor in Second Language Acquisition.

\section{Data Analysis}

The information gathered from the students regarding their progress in proficiency in reading, writing, speaking, and listening in English as well as their proficiency in their first language (Arabic) was subjected to a quantitative data analysis. Specifically, linear regression was used in order to determine the relationship of independent variables with that of the dependent variable.

For the qualitative analysis, the following steps were employed. The answers to the multiple-choice questions of the questionnaires were tabulated to determine patterns or themes and percentages that would lead to a more comprehensive understanding of the participants' view. The open-ended answers were first prepared and read carefully to search for any emerging themes. Different segments of the open-ended answers were categorized and coded. These segments were then organized according to common themes to arrive at an ample view of the population being studied as it related to the research problem. To confirm the themes obtained from this process, the NVivo 8 program was also utilized to analyze the answers of the participants and to come up with themes.

\section{Results}

For the statistical analysis, a series of linear regressions was performed in order to determine the impact of the first language literacy skills of adolescents living in Methnab on acquisition of their second language, which in this case is English. Linear regression was appropriate for the study because it analyzes the relationship between two variables, $X$ and $Y$. The $Y$ variable is the dependent variable, which in this case are the ELA Tests and the total growth as measured through AMAO. The $X$ variable refers to the independent variable of the study, which in this case is the Arabic Test Scores or the students' literacy level in their first language. A separate analysis for the two dependent variables was performed to differentiate and analyze thoroughly the effect of the first language score on that of the measures of the second language acquisition of the students. The hypotheses tested for this statistical analysis were

H0: The first language literacy skills of Methnab adolescents have no relation to their English language learning/acquisition.

Ha: The first language literacy skills of Methnab adolescents significantly facilitate their English language learning/acquisition. 
Total growth as per AMAO and Arabic Tests. The first pair of variables to be analyzed was the total growth AMAO and Arabic Tests. As previously mentioned, the independent variable is the Arabic Tests (City) and the dependent variable is the total growth AMAO. Before starting the regression analysis, the assumption of the linearity was assessed because if this was violated, the findings for the regression could be void and misleading.

For the statistical analysis, a series of linear regressions was performed in order to determine the impact of the first language literacy skills of adolescents living in Methnab on acquisition of their second language, which in this case is English. Linear regression was appropriate for the study because it analyzes the relationship between two variables, $X$ and $Y$. The $Y$ variable is the dependent variables, which in this case are the ELA Regents and the total growth as measured through AMAO scores. The $X$ variable refers to the independent variable of the study, which in this case is the Arabic Tests, or the students' literacy level in their first language. A separate analysis for the two dependent variables was performed to differentiate and analyze thoroughly the effect of the first language score on that of the measures of the second language acquisition of the students

Table 5 shows the resulting coefficients of the regression line. The result states that the expected total growth as measured by AMAO1 is equal to $1.40 \mathrm{x}$ Arabic Tests - 5.06. This means that if a student has 90 as the Arabic Tests score, then the expected total growth of its English proficiency as $\mathrm{m}$

Table 5. Total Growth AMAO and Arabic Regression Coefficients

\begin{tabular}{lcclll}
\hline $\begin{array}{l}\text { Unstandardised } \\
\text { coefficient }\end{array}$ & \multicolumn{2}{l}{$\begin{array}{l}\text { Standardized } \\
\text { coefficient }\end{array}$} & $t$ & Sig. \\
\hline$B$ & \multicolumn{5}{c}{ Std error } \\
\hline (Constant) & 5.06 & & 57.21 & 1.14 & 0.27 \\
\hline Arabic Tests & 1.40 & 0.72 & 0.13 & 0.55 & 0.09 \\
\hline
\end{tabular}

Measured by AMAO would be 1.40 x $90-5.06=120.94$.

Eighty percent of the students who scored 90 and above in the City Arabic Tests also showed the expected growth in the annual examination Tests; this is evidenced by the AMAO. However, one student, who represents $20 \%$ of this group, remained at the same proficiency level for 2 consecutive years. For the 2011-2012 school year, there was no considerable progress whereas the following year, in 2012, although the students remained at the same proficiency level, the total AMAO shows considerable progress for that year; the difference between the total annual examinations' scores for 2011 and 2012 is 43, which indicates progress.

ANOVA was used to test the acceptability of the model from a statistical perspective (see Table 6). The Regression row refers to the variation accounted for by the model developed and the Residual row refers to the variation that is not accounted for by the model developed. Most importantly, the results show that the $p$-value of the $F$ statistic is greater than 0.05 ; thus, the variation explained by the model is due to chance. This means that a fluctuation from the norm could have happened by pure chance. In the context of the study, it can mean that for the students, according to the Arabic Score, who have not achieved proficiency in the first language but reached the Advanced or Proficiency level in English within 3 years as per the annual examination results, this happened only by chance.

Table 6. Total Growth AMAO and Arabic ANOVA

\begin{tabular}{|c|c|c|c|}
\hline Sum of squares & $d f$ & Mean square & Sig. \\
\hline Regression & 468.04 & 468.04 & 0.31 \\
\hline Residual & 25912.38 & 17.00 & 1524.26 \\
\hline Total & 26380.42 & 18.00 & \\
\hline
\end{tabular}

The model summary, on the other hand, shows the strength of the relationship between the dependent variable and the model developed. Specifically, the multiple correlation coefficient $(R)$ refers to the linear correlation between the observed and model-predicted values of the dependent variable. The larger the value of $R$, the stronger the relationship; however, the results show a small value of $R$, which means that there is a weak correlation (see Table 7). Moreover, $\mathrm{R}$ square refers to the coefficient of determination, which is the squared value of the multiple correlation coefficient. It shows that only $2 \%$ of the variation in total growth in AMAO is explained by the model. Though the relationship, as expressed by the correlation coefficient, is weak; it does exist. As a matter of fact, all the ELLs who reached at least the Advanced level within 3 years scored between 84 and 94 in the Arabic Tests, except for one who scored lower. The latter remained at the Intermediate level for 2 years before moving to the advanced level, whereas more than two-thirds of those who either achieved proficiency or reached the 'Advanced' level within 3 years scored between 80 and 94 in the Arabic Language. 
Table 7. Total Growth AMAO and Arabic Model Summary

\begin{tabular}{llll}
\hline$R$ & $R$ square & Adjusted $R$ square & Std error of the estimate \\
\hline 0.13 & 0.02 & -0.04 & 39.04
\end{tabular}

In conclusion, the impact of Arabic was found to be significant but of little relation to that of the total growth AMAO. This means that if the Arabic score of a student is high, the total growth AMAO score will also be high. Indeed, the students who scored between 84 and 94 showed tremendous progress and demonstrated proficiency in the English language within 3 years; $80 \%$ of those who scored between 80 and 94 in the Arabic language demonstrated progress and attained a high level of proficiency; they are either at the 'Advanced' level or have achieved proficiency as evidenced by the annual examination results.

ELA Test-Scores and Arabic Test Scores: The second pair of variables analyzed was the ELA Test Scores and Arabic Test Scores. As previously mentioned, the independent variable is the Arabic Test Scores and the dependent variable is the ELA Test Score. Before starting the regression analysis, the assumption of the linearity was assessed.

Table 8 shows the result of the regression analysis. The result states that the expected ELA Test Score is equal to 34.63 $\mathrm{x}$ Arabic Test Score - 0.32. This means that if a student has a 90 as Arabic Test Score, then the ELA would be $34.63 \mathrm{x}$ $90-0.32=3116.38$. Such a result is indeed not permissible because it is too high and it can be seen that the significance of the model is above 0.05 , which means that the developed model with the dependent and independent variables is not a good combination.

Table 8. ELA Test and Arabic Test score Regression Coefficients

\begin{tabular}{llcrcc}
\hline $\begin{array}{l}\text { Un-standardized } \\
\text { coefficient }\end{array}$ & \multicolumn{1}{c}{$\begin{array}{l}\text { Standardized } \\
\text { coefficient }\end{array}$} & $t$ & \multicolumn{2}{c}{ Sig. } \\
\hline$B$ & & Std error & & Beta \\
\hline (Constant) & 34.63 & 22.08 & 0.27 & 1.57 & 0.14 \\
\hline Arabic Test & 0.32 & 0.28 & 0.26 \\
\hline
\end{tabular}

ANOVA was used to test the acceptability of the model from a statistical perspective (see Table 9). The Regression row refers to the variation accounted for by the model developed and the Residual row refers to the variation that is not accounted for by the model developed. The sums of the squares of the regression and the residual are not nearly equal, inferring that the model does not even explain half of the variation in the ELA Test Scores. Most importantly, the results show that the $p$-value of the $F$ statistic is greater than 0.05 ; thus, the variation explained by the model is due to chance.

Table 9. ELA Score

\begin{tabular}{|c|c|c|c|c|c|}
\hline ELA Score & $d f$ & & Mean square & $F$ & \\
\hline \multicolumn{6}{|l|}{ Arabic } \\
\hline Regression & 307.33 & 1 & 307.33 & 1.35 & .26 \\
\hline Residual & 3860.67 & & 17 & & 227.10 \\
\hline Total & 4168.00 & & & 18 & \\
\hline
\end{tabular}

Thus, this means that it cannot be ascertained statistically and would happen all the time that students who did well in Arabic Tests will demonstrate fluency in the English language. The fact that $20 \%$ of the students, who scored in the 80 s in Arabic, happened to fail the ELA and $60 \%$ barely passed; they scored under 75 , the score accepted by most of the Schools/colleges; half of the students who scored under 75 in Arabic failed the ELA Tests indicate these instances.

Table 10 is used to explicate the variation in the dependent variable. Table 10 shows the strength of the relationship between the dependent variable and the model developed. Specifically, the multiple correlation coefficient $(R)$ refers to the linear correlation between the observed and model-predicted values of the dependent variable. The larger the value of $R$, the stronger the relationship; however, the results show a small value of $R$, which means that there is a weak correlation (see Table 10). Moreover, $\mathrm{R}$ square refers to the coefficient of determination, which is the squared value of the multiple correlation coefficient. It shows that the small value (nearly 0) of $R$ square indicates that the model developed is not good enough in predicting the behavior of the variables. 
Table 10. ELA Tests and Arabic Tests Model Summary

\begin{tabular}{llll}
\hline$R$ & $R$ square & Adjusted $R$ square & Std error of the estimate \\
\hline 0.272 & 0.074 & 0.019 & 15.07 \\
\hline
\end{tabular}

A residual is the difference between the observed value and the model-predicted value of the dependent variable.

In conclusion, the facilitation-factor of Arabic language is found not to be significant and to have no relationship with that of the ELA Test results. This means that the score obtained by a student on each of these tests would not in any way affect the score of the other. The results serve as evidence. Indeed, students who demonstrate proficiency in French do not all show academic fluency in English; in fact, students who scored between 80 and 94 in Arabic Test would be expected to score at least 75 in the ELA Tests, which is the acceptable score for college/school readiness, but approximately half of these students barely passed, scoring between 65 and 70.82

\subsection{Students' Perceptions of Their Progress towards Developing Proficiency in the English Language}

Students' responses to the questionnaire were examined in light of the research question. Students expressed their awareness of the importance of first language literacy skills in the development of a second language: specifically, that the first language is used to facilitate understanding of materials written in the second language. Approximately $97 \%$ of the students who scored between 80 and 95 in the Arabic Tests; they claimed that they refer to the first language before and during reading a text in English. They look for familiar words, including words having the same cognates as words in their first language. They make associations with what they know in their first language and also use reading skills learned in the first language such as understanding words through context, summarizing, using prior knowledge, and so on. On the contrary, those who failed the Arabic Tests and those who were not recommended for the exam because of their low literacy level claimed that first language literacy skills do not help them much; this is understandable because they are not literate in the first language. They are, however, slowly progressing; targeted intensive instruction in which the four modalities of the English language are addressed may be the factors that have somewhat contributed to their progress.

The themes that emerged during the study were both a challenge and a help, which were addressed in conjunction with students' perception of their first language literacy in relation to their learning experience of the second language. Approximately $80 \%$ of the students revealed that their first language helps in the learning of the second language.

They claimed that when they were reading, they looked for similar words and used their prior knowledge to help them understand the materials in the new language. Some of them claimed that they also used a bilingual dictionary. On the other hand, more than half professed that difficult words and word-pronunciations presented a challenge in learning the English language. Even the students, who had demonstrated proficiency at an early stage, within 1 or 2 years, found that pronunciation and difficult words were hindrance in learning the new language.

To facilitate the process, it is advised that teachers plan targeted listening activities, providing opportunities for the students to practice listening to help them with word-pronunciation. Furthermore, although ESL teachers usually plan activities to promote the development of listening skills, it is also advised that ELLs are mainstreamed sometime during the school day to give them the opportunity to communicate with native English speaking peers in order for them to develop native-like oral communication skills.

\subsection{Teachers' Perception of Students' Progress}

Teachers were surveyed in order to get their perspectives of the students' progress. These teachers at some point taught the participating ELLs and were all trained in using Quality Teaching for English Learners strategies to reach the ELLs in their classroom. Thus, the information that was gathered from them is reliable and valid. In this section, certain questions from the survey are addressed to gain insights on the students' progress and the factors that contribute to their progress from the perspective of the teachers.

According to the teachers surveyed, 'Beginner' ELLs are not quite proficient in their first language (see Table 3 for results) as compared to the 'Intermediate' and 'Advanced' level ELLs whom they deemed to have a level of somewhat 'Proficient' in their first language. Teachers were also asked which group seemed to be moving more quickly towards achieving proficiency in the English language; they reported that it was the literate group of ELLs who were indeed moving more quickly. Out of 10 teachers, seven claimed this perspective. The teachers believed that ELLs arrive with different proficiency levels; this is also confirmed by the results of the Arabic Tests, which evaluate the participating ELLs' literacy ability in the first language. Indeed, students who scored below 70 in the Arabic Test results either did not show considerable progress as per the AMAO or remained at the same proficiency level. Furthermore, students who failed the Arabic Tests and those who were not recommended to take the exam because of their low literacy level did very poorly and remained at the 'Intermediate' level in developing proficiency in English.

Teachers also believed that second language acquisition occurs somewhat naturally for the students. However, they also believed that conversation can help students acquire the language more quickly and easily. According to the teachers, beginner ELLs engage in academic conversation less as compared to intermediate and advanced ELLs, which is why the former has a low rating for second language acquisition. Reading was also deemed to be an important factor to help students in achieving English proficiency. According to the teachers, across the different groups of ELLs, all were encouraged to read at home. 
Finally, teachers were asked if they believed that students' first language contributes to their second language acquisition; they reported that it is certainly a significant contributing factor. Nine out of 10 surveyed teachers answered that the students' first language contributes much to their second language acquisition. Teachers' responses also show that there is a relationship between students' home environment and their literacy development. Although the students are all encouraged to read at home, $90 \%$ of the teachers believe that the 'advanced' students display a more positive attitude towards reading. The students who achieve proficiency in a timely manner not only are encouraged to read at home but also read for pleasure and are highly literate in their first language; after all, they scored between 84 and 94 in the Arabic Tests. No wonder these students, as confirmed by both the students and their teachers' responses, refer to the reading strategies learned in their first language when they are reading in English. This would not happen if they were not literate in their first language.

Transfer of the literacy skills would not occur; logically, if the skills were not present; there would not be anything to transfer. Ninety percent of the teachers attested to the transfer of skills; they asserted that the transfer of first language literacy skills facilitates second language acquisition. In that regard, they believe that literacy skills learned in the first language can be transferred to the second language acquisition, thus enabling a specific student to learn more and more quickly in terms of the second language. To that effect, $60 \%$ of the teachers qualified the relationship between first language literacy and second language literacy as Excellent, 30\% Good, 10\% Fair, and none Poor. Thus, the teachers strongly believe that first language proficiency influences the development of the second language. Their responses to the questionnaire provide evidence of the impact of first language literacy on second language acquisition and enhance the understanding of the relationship that exists between the two variables.

\section{Conclusion}

The scope of the study was limited to two Methnab public high schools and covered only adolescent ELLs. For this reason the study may not be generalizable beyond the scope of this school and the participants because the data collection for the study was limited to surveying the selected participants. However, the findings could be used as support and additional knowledge in the field of language acquisition. Limitations include the purposeful sampling strategy used to select the data.

The results identify the potential benefits of enhancing one's knowledge and strategies for improving ELL students' English language acquisition. The study reveals the importance of holistically viewing the different aspects of a student that must be examined and improved for a faster and more efficient method of language acquisition development. According to August and Shanahan (2006), literacy in the English language is hierarchically developed; that is, certain skills cannot be acquired until other skills are mastered. For instance, before attaining a satisfactory level of reading comprehension, students must have developed the skills enabling them to decode and recognize words. Language follows certain structure and conventions. Being aware of the relationship that exists between the reading skills previously learned in the first language and what the students are currently exposed to in the second language, educators of ELLs will be more inclined to build on students" prior knowledge. They will use reading comprehension skills learned in the first language as a foundation for building new knowledge, therefore, promoting the second language.

The findings of this study also highlight the importance of students' first language in learning or acquiring a second language. As previously mentioned, there is a misconception of forbidding ELLs to use their first language, thinking that this motivates them to use English to communicate with their native language-speaking peers. However, as proven by the statistical analysis, first language really does have a significant impact on the second language acquisition; thus, this could promote a more positive attitude towards the advantages of using a first language for speakers/learners of other languages and, consequently, educators may decide to embrace and implement new strategies in which learners' previously learned literacy skills in a first language might be used as a scaffold for learning a second language.

\subsection{Recommendations}

1. The quantitative results of the study suggest that educators must consider the importance of first language skills of students to the acquisition of their second language acquisition skills.

2. It is recommended that in order to fully develop students' proficiency in the language being acquired, educators must design activities that promote the development of all four modalities of that language: reading, writing, speaking, and listening.

3. Furthermore, it is recommended for future research to dwell on the affective factors that can facilitate the second language learning/acquisition of students.

4. Social attitudes such as gender roles and community views towards language learning have also proven critical (Lyster \& Mori, 2006).

5. Also, the motivation of the individual learner is of vital importance to the success of language learning. Studies have consistently shown that intrinsic motivation, or a genuine interest in the language itself, is more effective over the long term than extrinsic motivation, as in learning a language for a reward such as high grades or praise (Ellis, 2002).

6. Language learning can be severely hampered by cultural attitudes. Further research is needed in this area to determine the help that individuals' cultural attitudes may have on their learning of a second language.

7. Social factors such as students' environment (family, religion, friends, economic status, etc.) and attitude towards learning may also influence the learning of a new language. It is, therefore, recommended that future 
research be conducted to study the role that these factors may play in the process of acquiring a second language.

8. The students should be taught English language by direct method. This option will be better to make the pupil understand the context and meaning.

9. If direct method of teaching is not possible, as in case of government schools in KSA, the indirect method may be used. It is also referred to as translation method. First the student thinks in his first language and then relates the nouns and grammar learnt in his first language to the second language.

10. Now that Information Technology is in place in all the advanced countries, ITC may be brought into use. Audio-visual aids and relative tools will facilitate quick grasp of the second language.

11. The teachers have to make it a point to impress upon the students the necessity of learning English in the interest of their country and for personal advancement. The teachers have to be trained in the use of tools, aids, charts, methods and approaches to manage the classroom situations with competency. They have to speak in English language not only in the class rooms but also outside the class rooms.

12. Group discussion, dialogue and conversation are better methods to teach English.

13. The students have to be encouraged to make presentations in the class. These can take many forms like paper reading, debate, declamation, question-answer sessions (Quiz), extempore speech, etc.

14. English language may be introduced as compulsory subject in the country from the beginning so that the prejudice against English as a foreign language does not form negative attitude towards English language.

\section{References}

Bialystok, E. (2001). Bilingualism in development: Language, literacy, and cognition. New York, NY: Cambridge University Press.

Boyd, F. B., Brook, C. H., Rozendal, M. S. (2004). Multicultural and multilingual literacy and language: Contexts and practices. New York, NY: The Guilford Press.

Brooks, J. G., \& Brooks, M. G. (1999). In search of understanding: The case for constructivist classrooms. Alexandria, VA: Association for Supervision and Curriculum Development.

Bryant, D. P., Smith, D., \& Bryant, B. R. (2008). Teaching students with special needs in inclusive classrooms. Boston, MA: Allyn \& Bacon.

Burt, M., Peyton, J. K., \& Adams, R. (2003). Reading and adult English language learners: The role of first language. Washington, DC: Center for Applied Linguistics.

Butler, S. M., \& McMunn, N. D. (2006). A teacher's guide to classroom assessment: Understanding and using assessment to improve student learning. San Francisco, CA: Jossey-Bass Teacher.

Calderon, M., \& Minaya-Rowe, L. (2003). Designing and implementing two-way bilingual programs: A step-by-step guide for administrators, teachers, and parents. Thousand Oaks, CA: Corwin Press.

Campbell, L., Campbell, \& B., Dickinson, D. (2004). Teaching and learning through multiple intelligences.

Chamot, A., Barnhart, S., El-Dinary, P., \& Robbins, J. (1999). The learning strategies handbook. White Plains, NY: Pearson Education/Longman.

Creswell, J. W. (2003). Research design: Qualitative, quantitative, and mixed methods approaches. Thousand Oaks, CA: Sage.

Creswell, J. W. (2005). Educational research: Planning, conducting, and evaluating quantitative and qualitative research. Upper Saddle River, NJ: Pearson Education.

Cummins, J. (2000). Language, power, and pedagogy: Bilingual children in the crossfire. Clevedon, England: Multilingual Matters.

Cummins, J. (2001). Bilingual children's mother tongue: Why is it important for education? Degraff, Ellis, R. (2002). Does form-focused instruction affect the acquisition of implicit knowledge? Studies in Second Language Acquisition, 24(2), 223-236.

Garcia, E. (2005). Teaching and learning in two languages: Bilingualism and schooling in the U.S. York, NY: Teachers College Press.

Johnson, R. B., \& Onwuegbuzie, A. J. (2004). Mixed methods research: A research paradigm whose time has come. Educational Researcher, 33(7), 14-26.

Kakkar, S. B. (2004). Educational psychology. New Delhi: Prentice Hall of India.

Krashen, S. D. (2002b). Second language acquisition and second language learning: The role of the first language in second language acquisition (Internet ed.). Retrieved from http://www.sdkrashen.com/SL_Acquisition_and_Learning/index.html (Originally published 1981) 
Lyster, R., \& Mori, H. (2006). Interactional feedback and instructional counterbalance. Studies in Second Language Acquisition, 28(2), 269-300. 99

Mayer, R. (2004). Learner as an information processor: Legacies, and limitation of educational psychology‘s second metaphor. Educational Psychologist, 31(3/4), 151-161.

Author. Piaget, J. (2000). The psychology of the child. New York, NY: Basic Books. (Original work published 1969)

Piaget, J. (2001). Psychology of intelligence. London, England: Routledge. (Original work published 1947)

Taylor-Powell, E., \& Renner, M. (2003). Analyzing qualitative data. Madison: University of Wisconsin Cooperative Extension.

Tomlinson, C. A., \& McTighe, J. (2006). How to differentiate instruction in mixed-ability classrooms. Alexandria, CA: Association for Supervision and Curriculum Development.

Tracey, D. H., \& Morrow, L. M. (2006). Lenses on reading: An introduction to theories and models. New York, NY: The Guilford Press.

Vygotsky, L., Rieber, R. W., Robinson, D. K., \& Bruner, J. S. (2004). Psychology: The essential of Vygotsky. New York, NY: Plenum.

Alexandria, VA: Association for Supervision and Curriculum Development.

Woolfolk, A. (2004). Educational psychology. Boston, MA: Allyn \& Bacon.

Yin, R. (2006). Mixed methods research: Are the methods genuinely integrated or merely parallel? Research in the Schools, 13(1), 41-47. 